\title{
Studies in Clinical Shock and Hypotension. II. Hemody- namic Effects of Norepinephrine and Angiotensin *
}

\author{
Jay N. Cohn † and Myron H. Luria $\ddagger$ \\ (From the Veterans Administration Hospital and the Department of Medicine, Georgetoren \\ University School of Medicine, Washington, D. C.)
}

Although vasoconstrictor drugs have been widely used for many years in the treatment of hypotension and shock, their clinical value is still the subject of much controversy (1). Norepinephrine has been recommended for support of the blood pressure in shock occurring in a wide variety of clinical settings (2-5), but Nickerson (6) claims that its vasoconstrictor effect is deleterious and that it increases blood pressure at the expense of a further reduction in blood flow.

Studies of the hemodynamic effects of norepinephrine in animal shock models have given conflicting results. The rise in blood pressure induced by norepinephrine in hemorrhagic shock in dogs has been attributed to increases in cardiac output in some studies (7-9), but others have shown increases only in peripheral resistance $(10)$ or in both output and resistance (11). Circulatory effects also have been shown to vary at different stages of the hemorrhagic shock procedure (12, 13).

Hemodynamic responses to norepinephrine have been studied extensively in normal subjects, but observations in hypotensive patients have been limited because of the difficulties encountered in performing studies on such acutely ill individuals. Gilbert and his associates (14) reported a slight fall in cardiac output during the infusion of norepinephrine in four patients with septic shock, whereas one of two hypotensive patients studied by Sambhi, Weil, Udhoji, and Rosoff (15) exhibited an increase in cardiac output. Smulyan, Cuddy, and Eich (16) found that norepinephrine increased the cardiac output in three of six patients

* Submitted for publication February 17, 1965 ; accepted May 20, 1965.

† Address requests for reprints to Dr. Jay N. Cohn, Veterans Administration Hospital, Washington, D. C.

$\ddagger$ Work performed while a U. S. Public Health Service trainee, National Heart Institute. with shock associated with sepsis or myocardial infarction.

The introduction into clinical use of synthetic angiotensin II has made available a nonadrenergic vasoconstrictor agent that has been advocated for the treatment of clinical hypotension (17-19). Although numerous reports have attested to its potency as a pressor agent in man (20-24), some authors have warned against its clinical use, particularly in cardiogenic shock (25-27), because of suspected adverse effects on myocardial function.

The present report analyzes hemodynamic data obtained at the bedsides of hypotensive patients during the infusion of norepinephrine and angiotensin. The results indicate that the effects of these drugs are different and that the hemodynamic response in hypotension may vary depending on the circulatory status of the patient when therapy is initiated.

\section{Methods}

Patients. Thirty-one male patients on the medical wards of the Veterans Administration Hospital were studied. All were critically ill and had either become acutely hypotensive or were in a state recognized by the attending physician as clinical shock, characterized by cool, moist skin, low or unobtainable auscultatory blood pressure, oliguria, and disturbed mentation. Hypotensive patients were studied in the absence of other clinical signs of shock if, in the course of a severe medical illness, systolic blood pressure fell to levels below $90 \mathrm{~mm} \mathrm{Hg}$ and the attending physician felt that pressor therapy was urgently required. Patients with a history or signs of significant blood loss were excluded. In many, the precise cause of the hypotensive episode was not clear to the attending physicians at the time of study. Table I lists the established diagnoses that may have been important in the development or persistence of the hypotensive state in these 31 patients. The patients ranged in age from 37 to 84 years with a mean of 61.7 years. They had diseases often involving multiple systems with a high incidence of complicating infections.

Procedures. Studies were performed at the bedside by a method previously described (28). Femoral arterial 
TABLE I

Diagnoses in 31 hypotensive patients*

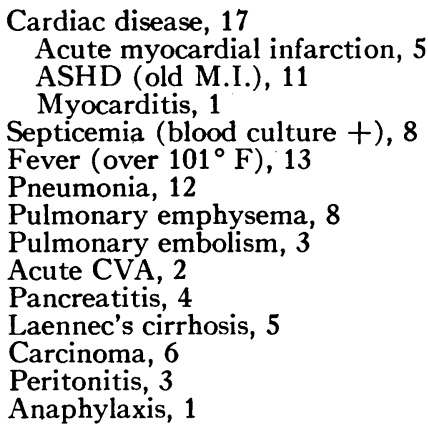

* ASHD $=$ arteriosclerotic heart disease; M.I. = myocardial infarction; CVA = cerebrovascular accident.

pressures were recorded through a Cournand needle, using a $\mathrm{P} 23 \mathrm{Db}$ strain gage transducer, ${ }^{1}$ carrier preamplifier, and two-channel direct writing recorder. ${ }^{2}$ Right atrial pressure was measured from a vinyl catheter advanced into the heart through a 14-gauge thin-wall needle in the femoral vein. Mean pressures were obtained by electrical integration. Cardiac output was determined by the dye dilution method. Indocyanine green was injected rapidly into the right atrium while femoral arterial blood was drawn through a cuvette densitometer ${ }^{3}$ by a constant rate withdrawal pump. ${ }^{3}$

Some of the patients were studied either before the administration of vasopressor drugs or an hour or more after a pressor agent had been discontinued. After control hemodynamic observations, $l$-norepinephrine (Levophed) or angiotensin II 4 was begun at an infusion rate adjusted as well as possible to maintain systolic blood pressure between 100 and $120 \mathrm{~mm} \mathrm{Hg}$. Repeat hemodynamic studies were performed when blood pressure was stable with a constant infusion of the drug. In those patients in whom a pressor drug was being administered at the time of study, initial studies were performed during the infusion of either $l$-norepinephrine or angiotensin II. The drug was then stopped, and blood pressure was allowed to fall to a stable level before control hemodynamic observations were made. Norepinephrine was administered to 24 patients, and angiotensin was given on 31 occasions to 28 patients. In those subjects given both drugs, blood pressure was allowed to fall to a stable control level between the two drug infusions.

Cardiac output was calculated from the dye curves by the standard Stewart-Hamilton method (29). Values reported for cardiac output represent averages of at least two serial determinations varying less than $10 \%$. Total peripheral vascular resistance (PVR), left ven-

1 Statham Transducers, Inc., Hato Rey, Puerto Rico.

2 Sanborn Company, Waltham, Mass.

${ }^{3}$ Gilford Instrument Laboratories, Inc., Oberlin, Ohio.

${ }^{4}$ Supplied as hypertensin by Ciba Pharmaceutical Co., Summit, N. J. tricular stroke work (LVSW), and central blood volume (CBV) were calculated from the formulas:

$$
\begin{aligned}
& \operatorname{PVR}\left(\text { dyne-sec-cm }{ }^{-5}\right)=\frac{(\text { MAP-RAP }) \times 1,332 \times 60}{\text { CO }}, \\
& \operatorname{LVSW}(g-\mathrm{m}) \\
& =\frac{\mathrm{CO} \times \mathrm{MAP} \times 13.6}{\mathrm{HR} \times 1,000},
\end{aligned}
$$

and

$$
\text { CBV (ml) }
$$

$$
=\frac{\mathrm{CO} \times \mathrm{MTT}}{60} \text {, }
$$

where MAP is mean arterial pressure in millimeters $\mathrm{Hg}$; RAP is mean right atrial pressure in millimeters $\mathrm{Hg}$; $\mathrm{CO}$ is cardiac output in milliliters per minute; $\mathrm{HR}$ is heart rate; and MTT is mean transit time in seconds from the right atrium to the femoral artery, computed from the recorded dye curve and the dye appearance time corrected for delay in the sampling system.

Blood volume was measured using a calibrated injection of T-1824 (30). All measurements reported were performed during a control period when no pressor drug was being infused. At least four arterial blood samples were collected from 10 to 40 minutes after injection of $\mathrm{T}-1824$, and the slope of disappearance of the dye was extrapolated semilogarithmically to the time of injection for measurement of plasma volume. The long sampling time and extrapolation method were used to avoid inaccuracy because of delayed intravascular mixing. Total blood volume was calculated from the plasma volume using the arterial hematocrit, which was corrected for trapped plasma (31) and multiplied by 0.91 to correct for the discrepancy between large vessel and total body hematocrit (32). Blood volumes were determined by this method in 22 hospitalized male subjects without diseases known to affect blood volume. Average value in these control subjects was $69 \pm 8$ (SD) $\mathrm{ml}$ per $\mathrm{kg}$.

\section{Results}

Norepinephrine

Pertinent hemodynamic observations made during the administration of norepinephrine to 24 hypotensive patients are shown in Table II.

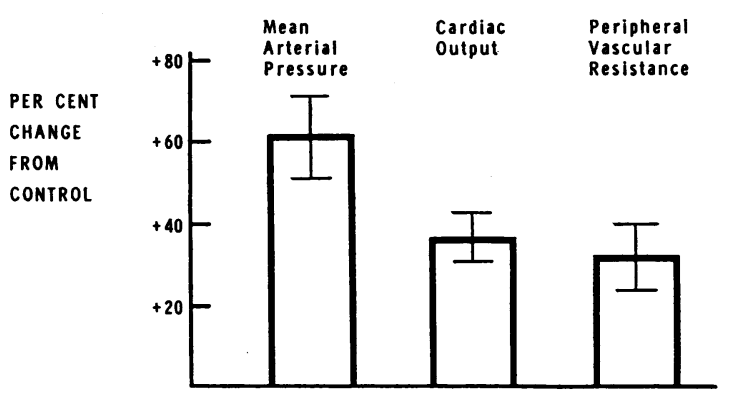

Fig. 1. Mean and Standard eRror of the hemodyNAMIC EFFECTS OF THE INFUSION OF NOREPINEPHRINE IN 24 HYPOTENSIVE PATIENTS. 
TABLE II

Hemodynamic effects of norepinephrine in 24 patients*

\begin{tabular}{|c|c|c|c|c|c|c|c|c|c|c|c|c|c|c|c|}
\hline \multirow[b]{2}{*}{ Patient } & \multirow[t]{2}{*}{$\begin{array}{l}\text { NE } \\
\text { dose }\end{array}$} & \multicolumn{2}{|c|}{$\begin{array}{c}\text { Mean } \\
\text { arterial } \\
\text { pressure }\end{array}$} & \multicolumn{2}{|c|}{ Heart rate } & \multicolumn{2}{|c|}{ Cardiac output } & \multicolumn{2}{|c|}{$\begin{array}{l}\text { Right atrial } \\
\text { pressure }\end{array}$} & \multicolumn{2}{|c|}{$\begin{array}{l}\text { Peripheral vascu- } \\
\text { lar resistance }\end{array}$} & \multicolumn{2}{|c|}{$\begin{array}{l}\text { Left ven- } \\
\text { tricular } \\
\text { stroke work }\end{array}$} & \multicolumn{2}{|c|}{$\begin{array}{l}\text { Central blood } \\
\text { volume }\end{array}$} \\
\hline & & $\mathrm{C}$ & $\mathbf{R}$ & C & $\mathbf{R}$ & $\mathrm{C}$ & $\mathbf{R}$ & $\mathrm{C}$ & $\mathbf{R}$ & $\mathrm{C}$ & $\mathbf{R}$ & $\mathrm{C}$ & $\mathbf{R}$ & $\mathrm{C}$ & $\mathbf{R}$ \\
\hline & $\mu g / \min$ & \multicolumn{2}{|c|}{$m m \mathrm{Hg}$} & \multicolumn{2}{|c|}{ beats/min } & \multicolumn{2}{|c|}{$\mathrm{ml} / \mathrm{min}$} & \multicolumn{2}{|c|}{$m m \mathrm{Hg}$} & \multicolumn{2}{|c|}{ dyne-sec-cm-5 } & \multicolumn{2}{|c|}{$g-m$} & \multicolumn{2}{|c|}{$m l$} \\
\hline H.C. & 24 & 54 & +22 & 160 & +25 & 2,180 & +350 & 6 & 0 & 1,761 & +452 & 10 & +3 & 1,054 & -168 \\
\hline c.C. & 48 & 32 & +36 & 126 & +16 & 2,885 & $+2,375$ & 3 & -1.5 & 804 & +207 & 10 & +24 & 841 & +211 \\
\hline C.H. & 48 & 50 & +40 & 114 & +4 & 3,601 & $+1,415$ & 12 & +7 & 844 & +288 & 21 & +31 & 1,530 & +58 \\
\hline S.C. & 16 & 58 & +18 & 66 & +8 & 1,900 & $+1,700$ & 2.8 & +1.8 & 2,324 & -737 & 23 & +17 & 1,235 & +865 \\
\hline J.F. & 2 & 66 & +18 & 54 & -4 & 4,925 & -25 & 1.2 & +2.8 & 1,053 & +253 & 82 & +30 & 1,272 & +123 \\
\hline W.C. & 16 & 44 & +24 & 120 & +6 & 2,343 & +547 & 10 & -3 & 1,161 & +528 & 12 & +9 & 1,308 & +65 \\
\hline C.Ch. & 1.5 & 64 & +12 & 66 & +6 & 4,165 & $+1,200$ & 22 & -4 & 806 & +59 & 55 & +22 & 2,256 & +114 \\
\hline C.D. & 2 & 56 & +16 & 84 & -18 & 4,540 & -200 & -2 & +4.5 & 1,022 & +259 & 41 & +23 & 1,324 & -22 \\
\hline W.U. & & 50 & +22 & 66 & +6 & 3,073 & +867 & 15 & -7 & 911 & +388 & 32 & +22 & 1,767 & +333 \\
\hline A.A. & 32 & 52 & +32 & 82 & +8 & 3,385 & $+1,972$ & 7 & +7 & 1,064 & -19 & 29 & +39 & 1,016 & +413 \\
\hline C.G. & 10 & 64 & +23 & 80 & +5 & 3,850 & +582 & 1 & +3 & 1,309 & +189 & 42 & +20 & 2,791 & +533 \\
\hline E.L. & 40 & 28 & +60 & 102 & +3 & 1,877 & $+2,184$ & 6 & 0 & 938 & +677 & 7 & +39 & 1,267 & +410 \\
\hline J.B. & 5 & 62 & +24 & 100 & +8 & 2,960 & +790 & 4.5 & -.5 & 1,554 & +195 & 25 & +16 & 1,145 & +230 \\
\hline G.B. & 12 & 56 & +34 & 96 & o & 4,030 & +557 & 1 & +1 & 1,092 & +443 & 32 & +26 & 833 & +39 \\
\hline L.H. & 25 & 40 & +34 & 60 & +18 & 8,290 & $+1,270$ & 15 & -1 & 241 & +264 & 75 & +48 & 1,796 & +36 \\
\hline R.W. & 16 & 48 & +14 & 132 & -6 & 1,724 & -7 & 0 & +4 & 2,227 & +475 & 9 & +3 & 1,178 & -205 \\
\hline C.S. & 39 & 61 & +39 & 75 & +15 & 2,654 & +11 & 9.5 & +.5 & 1,552 & $+1,150$ & 29 & +12 & 2,389 & +76 \\
\hline W.T. & 37 & 60 & +20 & 108 & 0 & 2,308 & +632 & 6 & -1 & 1,872 & +169 & 17 & +13 & 939 & +41 \\
\hline H.M. & 1.6 & 84 & +18 & 114 & 0 & 2,682 & +282 & 15 & -1 & 2,058 & +317 & 27 & +9 & 1,497 & +29 \\
\hline J.V. & 36 & 48 & +20 & 144 & $\mathbf{0}$ & 8,454 & $+5,826$ & 14.5 & +5.5 & 317 & -48 & 38 & +54 & 1,282 & +432 \\
\hline H.B. & 48 & 30 & +49 & 150 & o & 2,401 & $+1,855$ & 14.5 & -1.0 & 516 & +715 & 7 & +23 & 2,384 & -311 \\
\hline R.R. & 5.3 & 52 & +32 & 126 & +6 & 2,016 & +391 & 8 & 0 & 1,746 & +780 & 11 & +10 & 1,015 & +136 \\
\hline H.R. & 8 & 50 & +26 & 84 & +6 & 2,443 & $+1,944$ & 11.5 & -2.5 & 1,260 & -38 & 20 & +30 & 1,336 & +427 \\
\hline B.F. & 8 & 58 & +14 & 84 & -6 & 4,566 & -323 & -1 & 0 & 1,033 & +343 & 43 & +10 & 1,224 & +37 \\
\hline Mean & 21.0 & 53 & +27 & 99 & +5 & 3,468 & $+1,091$ & 7.6 & +0.7 & 1,228 & +304 & 29 & +22 & 1,444 & +164 \\
\hline p value & & \multicolumn{2}{|c|}{$<0.01$} & \multicolumn{2}{|c|}{$<0.01$} & \multicolumn{2}{|c|}{$<0.01$} & \multicolumn{2}{|c|}{$>0.4$} & \multicolumn{2}{|c|}{$<0.01$} & \multicolumn{2}{|c|}{$<0.01$} & \multicolumn{2}{|c|}{$<0.01$} \\
\hline
\end{tabular}

$* \mathrm{NE}=$ norepinephrine $; \mathrm{C}=$ control $; \mathrm{R}=$ response.

Blood pressure and heart rate. A satisfactory pressor response was obtained in all 24 subjects with a rise in mean arterial pressure averaging $61 \%$ of control levels (Figure 1). The dose of norepinephrine required ranged from 1.6 to 48 $\mu \mathrm{g}$ per minute and averaged $21 \mu \mathrm{g}$ per minute.

Heart rate increased slightly but significantly during the infusion of norepinephrine, rising from an average of 100 to 105 beats per minute. The changes were not striking in most patients and indicated that effects on heart rate were not of prime importance in the systemic response to the drug. Some patients developed evidence of myocardial irritability during the infusion, but premature beats usually could be controlled by slowing of the infusion rate. In no instances in this group of patients did an arrhythmia require discontinuation of the norepinephrine.

Cardiac output and peripheral vascular resistance. Cardiac output increased in all but five of the patients, rising by a mean of $1,091 \mathrm{ml}$ per minute $(34 \%)$ (Figure 1 ) during the infusion of norepinephrine. Control cardiac output was less than
$5 \mathrm{~L}$ per minute in 22 of the patients. In four of these the output was restored to a normal level by norepinephrine. Two subjects had high cardiac outputs in the control period. One (J.V.) had post-traumatic visceral arteriovenous fistulae, and the other (L.H.) had severe Laennec's cirrhosis. Both exhibited a further increase in output during norepinephrine infusion. Three of the five patients whose outputs failed to increase (J.F., C.D., and B.F.) had control cardiac outputs only slightly less than $5 \mathrm{~L}$ per minute and developed cardiac slowing during the administration of the drug.

Total blood volume was measured in 15 of the patients (Table III). Although none had a history suggestive of blood volume loss, the measured volume was more than $1 \mathrm{SD}$ below the predicted normal value in seven patients. Only one of these hypovolemic patients had a rise in cardiac output of over $700 \mathrm{ml}$ per minute during administration of norepinephrine, whereas five of the eight normovolemic patients augmented their outputs by more than 1,200 ml per minute (Figure 2 ).

Calculated peripheral vascular resistance was in- 
TABLE III

Control blood volumes measured in hypotensive patients subsequently given norepinephrine

\begin{tabular}{ccc}
\hline \hline Patient & Weight & Blood volume \\
\hline Normovolemic & $k g$ & $m l / k g$ \\
C.C. & 60 & \\
J.F. & 45 & 65 \\
C.C.h. & 61 & 90 \\
E.L. & 54 & 63 \\
J.B. & 50 & 71 \\
L.H. & 68 & 94 \\
H.M. & 40 & 85 \\
J.V. & 62 & 92 \\
& & \\
Hypovolemic & Mean & $80.6 \pm 5$ (SEM) \\
H.C. & 65 & 61 \\
W.C. & 86 & 45 \\
G.B. & 74 & 58 \\
R.W. & 70 & 41 \\
W.T. & 80 & 41 \\
H.B. & 55 & 59 \\
R.R. & 63 & 38 \\
& Mean & $49 \pm 4$ (SEM) \\
\hline
\end{tabular}

creased in 19 of the patients during the infusion, but in five patients resistance was essentially unchanged or actually fell. Resistance increased an average of $31.8 \%$ for the 24 patients (Figure 1). Left ventricular stroke work was increased strikingly during the administration of norepinephrine, as a result of an increase in both stroke volume and arterial pressure.

Central blood volume and right atrial pressure. Twelve patients had a measured increase of over $100 \mathrm{ml}$ in central blood volume during the infusion of norepinephrine. In three others central blood volume fell, whereas in the remaining eight patients no significant change was noted. The mean increase for the entire group was significant $(\mathrm{p}<0.01)$.

The importance of adequate blood volume for displacement into the central circulation can be noted from analysis of the 11 patients who did not experience a significant increase in central blood volume from norepinephrine. Blood volume was measured in seven of these patients, and in six it was reduced more than $1 \mathrm{SD}$ below the predicted normal value.

The mean change in right atrial pressure during norepinephrine infusion was not significant. Eleven patients had an elevated right atrial pressure during the control period, suggesting an element of right ventricular decompensation. In eight of these patients, administration of norepinephrine was associated with either no change or a fall in right atrial pressure. In the other three patients (C.H., A.A., and J.V.) rises in atrial pressure during the infusion were associated with marked increases in cardiac output.

\section{Angiotensin}

Pertinent hemodynamic observations made during the administration of angiotensin are shown in Table IV.

Blood pressure and heart rate. A rise of arterial pressure to normal levels was observed in all but three of the subjects. In these three (A.A., R.W., and J.V.) infusion rates ranging from 22.5 to 60 $\mu \mathrm{g}$ per minute failed to produce any increase in arterial pressure. The dose of angiotensin ranged from 0.3 to $60 \mu \mathrm{g}$ per minute and averaged 14.1 $\mu \mathrm{g}$ per minute.

No significant change in heart rate occurred during the infusion of angiotensin, the rate averaging

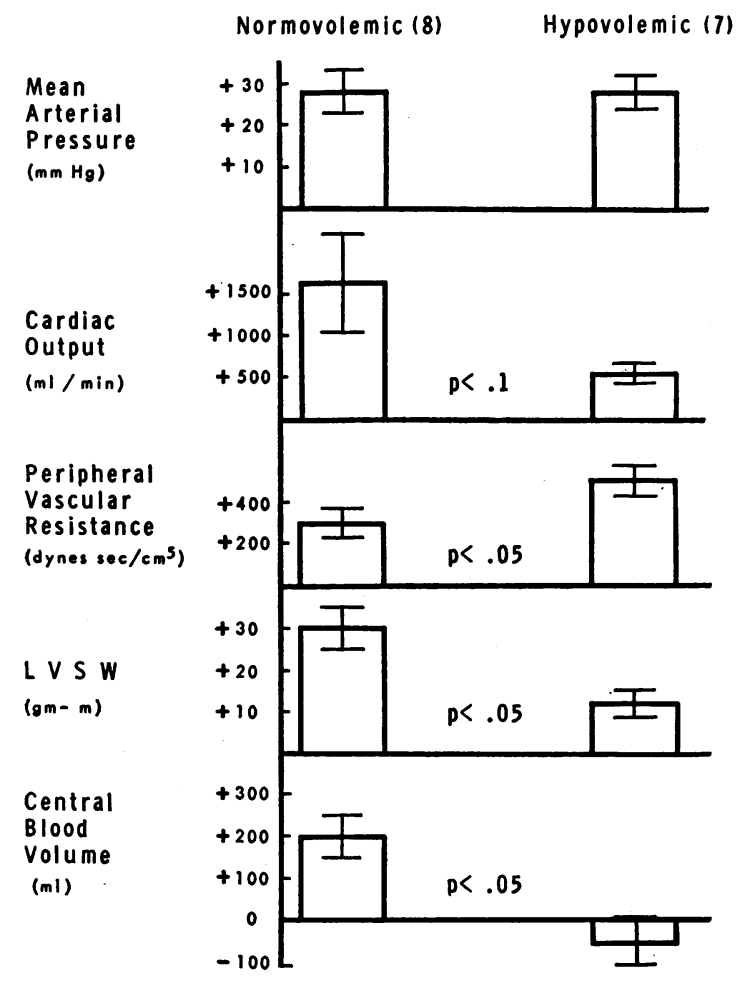

Fig. 2. Comparison of the hemodynamic Response TO NOREPINEPHRINE IN NORMOVOLEMIC AND HYPOVOLEMIC H YPOTENSIVE PATIENTS. Mean and standard error of the changes from control are shown. LVSW $=$ left ventricular stroke work. 
TABLE IV

Hemodynamic effects of angiotensin II in 28 patients

\begin{tabular}{|c|c|c|c|c|c|c|c|c|c|c|c|c|c|c|c|}
\hline \multirow[b]{2}{*}{ Patient } & \multirow[t]{2}{*}{$\begin{array}{l}\text { Angio- } \\
\text { tensin } \\
\text { dose }\end{array}$} & \multicolumn{2}{|c|}{$\begin{array}{c}\text { Mean arterial } \\
\text { pressure }\end{array}$} & \multicolumn{2}{|c|}{ Heart rate } & \multicolumn{2}{|c|}{ Cardiac output } & \multicolumn{2}{|c|}{$\begin{array}{l}\text { Right atrial } \\
\text { pressure }\end{array}$} & \multicolumn{2}{|c|}{$\begin{array}{c}\text { Systemic } \\
\text { vascular } \\
\text { resistance }\end{array}$} & \multicolumn{2}{|c|}{$\begin{array}{c}\text { Left } \\
\text { ventricular } \\
\text { stroke work } \\
\end{array}$} & \multicolumn{2}{|c|}{$\begin{array}{c}\text { Central blood } \\
\text { volume }\end{array}$} \\
\hline & & C & $\mathbf{R}$ & $\mathrm{C}$ & $\mathbf{R}$ & $\mathrm{C}$ & $\mathbf{R}$ & $\mathrm{C}$ & $\mathbf{R}$ & $\mathrm{C}$ & $\mathbf{R}$ & $\mathrm{C}$ & $\mathbf{R}$ & $\mathrm{C}$ & $\mathbf{R}$ \\
\hline & $\mu g / \min$ & \multicolumn{2}{|c|}{$m m \mathrm{Hg}$} & \multicolumn{2}{|c|}{ beats/min } & \multicolumn{2}{|c|}{$m l / \min$} & \multicolumn{2}{|c|}{$m m \mathrm{Hg}$} & \multicolumn{2}{|c|}{ dyne-sec-cm-5 } & \multicolumn{2}{|c|}{$g-m$} & \multicolumn{2}{|c|}{$m l$} \\
\hline K.C. & 8 & 66 & +28 & 130 & +2 & 2,940 & +835 & -4 & -0.5 & 1,905 & +189 & 20 & +17 & 1,397 & +277 \\
\hline H.C. & 15 & 54 & +22 & 160 & -20 & 2,180 & +105 & 6 & 0 & 1,761 & +690 & 10 & +7 & 1,054 & +50 \\
\hline C.C. & 13 & 32 & +16 & 126 & +2 & 2,885 & $+2,380$ & 3 & 0 & 804 & -120 & 10 & +17 & 841 & +273 \\
\hline C.H. & 20 & 46 & +20 & 114 & -6 & 3,671 & & 10 & +10 & 785 & & 20 & & 1,407 & \\
\hline S.C. & 1 & 58 & +26 & 66 & +18 & 1,900 & +100 & 2.8 & +0.8 & 2,324 & +892 & 23 & +4 & 1,235 & +105 \\
\hline J.F. & 2 & 66 & +14 & 54 & -4 & 4,925 & -621 & 1.2 & +0.8 & 1,053 & +397 & 82 & +12 & 1,272 & +55 \\
\hline R.T. & 17 & 53 & +11 & 120 & -12 & 2,355 & +415 & 4.5 & 0 & 1,648 & +128 & 14 & +9 & 1,079 & +6 \\
\hline W.C. & 12 & 44 & +40 & 120 & 0 & 2,343 & $+1,351$ & 10 & -6 & 1,161 & +572 & 12 & +23 & 1,308 & +385 \\
\hline W.U. & 5 & 50 & +20 & 66 & +2 & 3,073 & +335 & 15 & -10 & 911 & +615 & 32 & +16 & 1,767 & +249 \\
\hline W.M. & 16 & 64 & +16 & 105 & +3 & 5,050 & $-1,157$ & 19 & o & 713 & +541 & 42 & -3 & 2,003 & -11 \\
\hline A.A. & 60 & 52 & o & 84 & -6 & 3,120 & -372 & 8 & +9 & 1,128 & -109 & 26 & -1 & 1,014 & +259 \\
\hline C.G. & 4 & 64 & +20 & 80 & +5 & 3,850 & -449 & 1 & -1 & 1,309 & +667 & 42 & +4 & 2,791 & +43 \\
\hline E.L. & 7 & 29 & +53 & 110 & 0 & 2,152 & $+1,089$ & 6 & +5 & 855 & +898 & 8 & +25 & 1,381 & +212 \\
\hline J. B. & 10 & 62 & +31 & 100 & +2 & 2,960 & +100 & 4.5 & +0.5 & 1,554 & +747 & 25 & +13 & 1,145 & +181 \\
\hline B.B. & 2 & 72 & +28 & 120 & 0 & 4,245 & -180 & 8 & +4 & 1,206 & +526 & 35 & +11 & 1,698 & +504 \\
\hline G.B. & 15 & 56 & +28 & 96 & +12 & 4,030 & $+2,092$ & 1 & 0 & 1,092 & -7 & 32 & +33 & 833 & +340 \\
\hline L.H. & 45 & 40 & +26 & 60 & +4 & 8,290 & -290 & 15 & -1 & 241 & +279 & 75 & +37 & 1,796 & -23 \\
\hline R.W. & 25 & 48 & -2 & 132 & -6 & 1,724 & -230 & 0 & +2 & 2,227 & +129 & 9 & -2 & 1,178 & -20 \\
\hline C.S. & 5.4 & 61 & +31 & 75 & +42 & 2,654 & -240 & 9.5 & +3 & 1,552 & $+1,083$ & 29 & -3 & 2,389 & -358 \\
\hline P.H. & 0.3 & 60 & +14 & 78 & +6 & 3,128 & 0 & 9 & +3 & 1,304 & +282 & 33 & +4 & 1,335 & 0 \\
\hline W.T. & 5 & 60 & +16 & 108 & -6 & 2,308 & +496 & 6 & +0.4 & 1,872 & +114 & 17 & +11 & 939 & +61 \\
\hline J.P. & 4 & 62 & +24 & 102 & 0 & 4,425 & -65 & 1 & 0 & 1,102 & +458 & 37 & +13 & 811 & +25 \\
\hline H.M. & 2 & 84 & +18 & 114 & -6 & 2,682 & +315 & 15 & -1 & 2,058 & +291 & 27 & +11 & 1,497 & +226 \\
\hline J.V. & 22.5 & 48 & -8 & 144 & 0 & 8,454 & +86 & 14.5 & +0.5 & 317 & -83 & 38 & -6 & 1,282 & -1 \\
\hline H.B. & 16 & 30 & +56 & 150 & -6 & 2,401 & $+1,039$ & 14.5 & 0 & 516 & $+1,147$ & 7 & +21 & 2,348 & -469 \\
\hline H.B.(2) & 55 & 32 & +44 & 78 & 0 & 1,500 & +840 & 7 & -1 & 1,333 & $+1,007$ & 8 & +23 & 853 & +184 \\
\hline H.B. (3) & 2.5 & 28 & +42 & 60 & +15 & 3,365 & $+2,100$ & 9 & +2 & 452 & +412 & 21 & +48 & 1,211 & +372 \\
\hline R.R. & 6 & 52 & +40 & 126 & -6 & 2,016 & +451 & 8 & -0.8 & 1,746 & $+1,004$ & 11 & +15 & 1,015 & +79 \\
\hline H.R. & 35 & 50 & +34 & 84 & +6 & 2,443 & -774 & 11.5 & +3.5 & 1,260 & $\begin{array}{r}+409 \\
\end{array}$ & 20 & +2 & 1,336 & -87 \\
\hline E.G. & 4.5 & 46 & +26 & 108 & 0 & 3,180 & +127 & -4 & 0 & 1,257 & +581 & 18 & +12 & 620 & +7 \\
\hline E.G. (2) & 3.8 & 35 & +33 & 120 & +8 & 3,289 & +891 & 3 & 0 & 851 & +450 & 13 & +17 & 753 & -4 \\
\hline Mean & 14.1 & 51.8 & +24.7 & 102.8 & +1.6 & 3,340 & +359 & 6.9 & +0.7 & 1,235 & +473 & 24.8 & +13.0 & 1,343 & +98 \\
\hline $\mathrm{p}$ value & & \multicolumn{2}{|c|}{$<0.001$} & \multicolumn{2}{|c|}{$>0.5$} & \multicolumn{2}{|c|}{$<0.05$} & \multicolumn{2}{|c|}{$>0.2$} & \multicolumn{2}{|c|}{$<0.001$} & \multicolumn{2}{|c|}{$<0.001$} & \multicolumn{2}{|c|}{$<0.02$} \\
\hline
\end{tabular}

103 beats per minute during the control period and 104 beats per minute during angiotensin. Only rarely were arrhythmias noted, and these occurred only if the blood pressure was increased to excessive levels. In one patient (P.H.), ventricular irritability occurred repeatedly with an in-

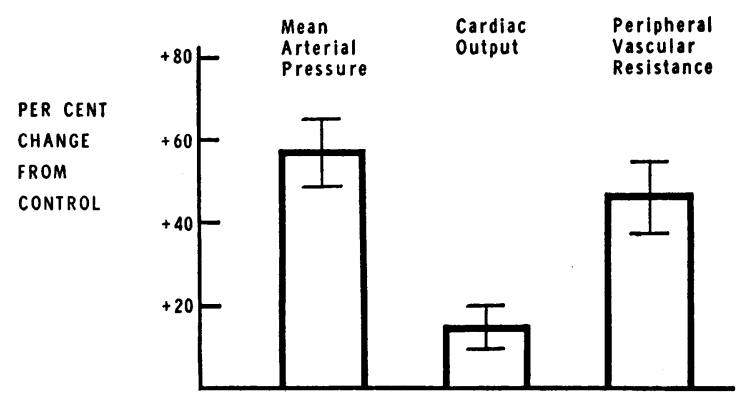

Fig. 3. Mean and STANdard ERROR OF the hemoDYNAMIC EFFECTS OF 31 INFUSIONS OF ANGIOTENSIN IN 28 HYPOTENSIVE PATIENTS. fusion of norepinephrine, but was not observed during administration of angiotensin.

Cardiac output and peripheral vascular resistance. Cardiac output increased by an average of $359 \mathrm{ml}$ per minute during the 30 angiotensin infusions in which it was measured $(p<0.05)$. The average change was an increase of $14.7 \%$ over control cardiac output (Figure 3 ). The output increased during 14 of the infusions, was unchanged in 9, and fell in the other 7.

Thirteen of the patients had evidence of congestive heart failure at the time of study, as evidenced by a significant elevation of right atrial pressure or signs of pulmonary congestion with an expanded central blood volume, or both. Cardiac output increased during infusion of angiotensin in five of these patients and remained the same or fell in seven. In one (C.H.), the infusion was stopped before the output could be recorded be- 
cause of clinical evidence of left ventricular failure. The output was increased in subjects with heart failure by an average of $80 \mathrm{ml}$ per minute, compared to an increase averaging $428 \mathrm{ml}$ per minute in those without heart failure. This difference was not statistically significant.

Five patients with acute myocardial infarctions received angiotensin. In one (E.L.) the cardiac output increased by over $2 \mathrm{~L}$ per minute. Three patients (C.G., B.B., and C.S.) exhibited slight falls in cardiac output, and in one (P.H.) cardiac output was unchanged.

There was no correlation between total blood volume and cardiac output response to angiotensin. Total blood volume was measured in 17 of the patients and was reduced more than 1 SD below the normal range in seven. Cardiac output increased by an average of $439 \mathrm{ml}$ per minute in the normovolemic group and by $729 \mathrm{ml}$ per minute in the hypovolemic subjects.

Calculated peripheral vascular resistance rose by an average of 473 dyne-sec- $\mathrm{cm}^{-5}$ during the angiotensin infusions. The mean change was an increase of $46.4 \%$ over control resistance (Figure $3)$. In four patients an increase in resistance did not occur. Two of these patients (A.A. and J.V.) apparently were resistant to the drug, since they received large doses without effect on arterial pressure or peripheral resistance. In the other two patients (C.C. and G.B.), calculated vascular resistance declined as a result of a marked increase in cardiac output.

Central blood volume and right atrial pressure. Central blood volume increased by an average of $98 \mathrm{ml}$ during infusion of angiotensin $(\mathrm{p}<0.02)$, and right atrial pressure rose insignificantly by $0.7 \mathrm{~mm} \mathrm{Hg}$. The adequacy of total blood volume appeared to have no influence on the changes noted in central blood volume. The increase in central blood volume with angiotensin averaged $136 \mathrm{ml}$ in the normovolemic patients and $153 \mathrm{ml}$ in the hypovolemic patients.

In three patients with signs of heart failure in the control period (C.H., A.A., and B.B.), progressive left ventricular failure accompanied the infusion of angiotensin. Patient B.B. became dyspneic and cyanotic with a rise of $504 \mathrm{ml}$ in central blood volume and a slight decrease in cardiac output. He recovered promptly when the infusion was discontinued. Patient A.A. had no pressor response to angiotensin, but he exhibited a rise of $259 \mathrm{ml}$ in central blood volume with a fall in cardiac output. His blood pressure fell progressively, and he expired shortly thereafter despite the administration of large doses of norepinephrine. Patient C.H. showed an initial well-tolerated rise in blood pressure to $112 / 70 \mathrm{~mm} \mathrm{Hg}$ with angiotensin. However, 7 minutes later, with the infusion at the same rate, a fall in blood pressure to $88 / 56 \mathrm{~mm} \mathrm{Hg}$ was accompanied by agitation, confusion, and dyspnea. He improved promptly when the angiotensin was discontinued and then responded satisfactorily to norepinephrine. Dye curves were not obtained during the angiotensin infusion.

Comparison between angiotensin and norepinephrine. The average increase in cardiac output that occurred during 24 infusions of norepinephrine $(1,091 \mathrm{ml}$ per minute) was significantly $(p<0.02)$ greater than the average increase of $359 \mathrm{ml}$ per minute during 30 infusions of angiotensin. In patients without heart failure, norepinephrine was only negligibly more effective

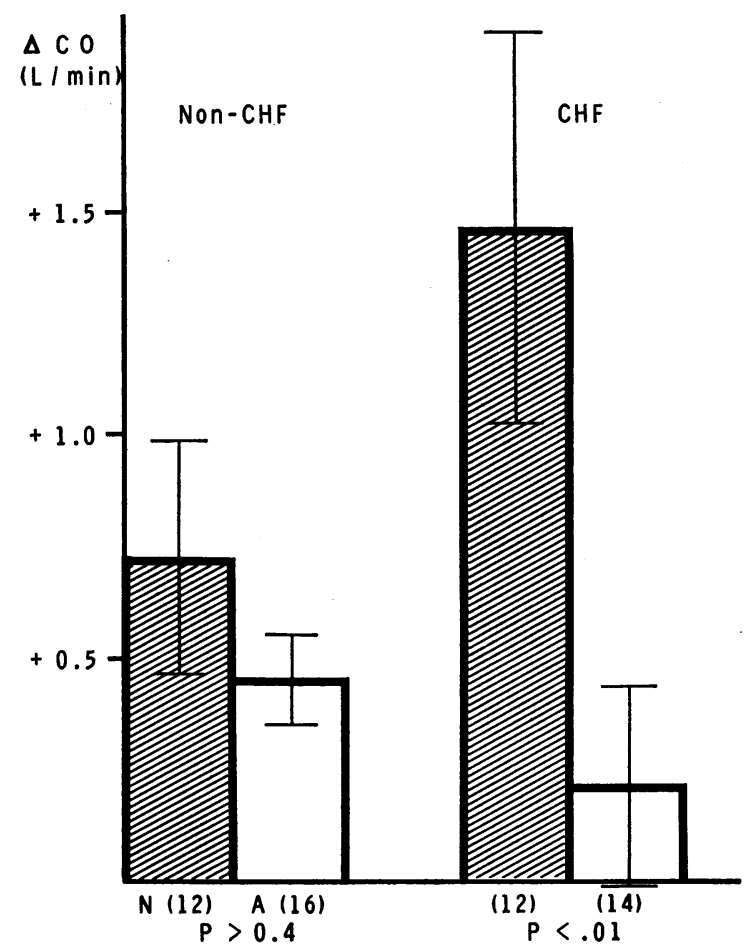

Fig. 4. Cardiac output (CO) RESPONSE to NOREPINEPHRINE (N) AND ANGIOTENSIN (A) IN HYPOTENSIVE PATIENTS WITH AND WITHOUT EVIDENCE OF HEART FAILURE. $\mathrm{CHF}=$ congestive heart failure 
than angiotensin, whereas in patients with hypotension and concomitant heart failure, norepinephrine produced a much greater augmentation of cardiac output (Figure 4).

Sixteen patients received separate infusions of norepinephrine and angiotensin in approximately equipressor doses. In these subjects, cardiac output during administration of norepinephrine averaged $3,936 \mathrm{ml}$ per minute and during angiotensin $3,394 \mathrm{ml}$ per minute $(\mathrm{p}<0.05)$. Peripheral vascular resistance averaged 1,700 dyne-sec- $\mathrm{cm}^{-5}$ during norepinephrine and 2,041 dyne-sec- $\mathrm{cm}^{-5}$ during angiotensin $(p<0.05)$. Heart rate, right atrial pressure, stroke work, and central blood volume were not significantly different. Blood volume was reduced more than $1 \mathrm{SD}$ below the predicted value in six of these patients. In these hypovolemic subjects, the average cardiac output during administration of angiotensin $(3,470 \mathrm{ml}$ per minute) was slightly higher than that during norepinephrine $(3,268 \mathrm{ml}$ per minute). In the seven patients with heart failure in this group, the cardiac output averaged $4,380 \mathrm{ml}$ per minute during infusion of norepinephrine and only $3,661 \mathrm{ml}$ per minute during angiotensin. No correlation was noted between the doses of these two drugs required to produce an equipressor effect. The ratio of the dose of norepinephrine to that of angiotensin required for a given patient ranged from $16: 1$ to $1: 4.5$.

\section{Discussion}

The cardiovascular effects of norepinephrine and angiotensin differ. Both agents produce arteriolar constriction $(20-24,33)$, but norepinephrine also causes venoconstriction that decreases the peripheral vascular capacity $(34,35)$, whereas angiotensin lacks significant venoconstrictor effect (36-38). Contractile force of the heart is markedly augmented by norepinephrine $(39,40)$, but many investigators have suggested that angiotensin is essentially devoid of myocardial stimulating properties $(21,23,41-44)$. In the isolated heart and heart-lung preparation, however, angiotensin has a prominent inotropic effect $(26,45-48)$. Although angiotensin may produce coronary vasoconstriction and a transient impairment of myocardial function (45-49), sustained infusions result in an improvement in ventricular performance. Berry, Austen, and Clark (49) reported a pro- longed increase in myocardial contractile force, and $\mathrm{Yu}$ and his associates (50) demonstrated increased cardiac work with a shift of the ventricular function curve to the left during administration of angiotensin.

In the intact subject, the pressor effect produced by norepinephrine and angiotensin stimulates baroreceptor activity, which tends to decrease heart rate and myocardial force and to dilate the peripheral vascular bed (51-53), often resulting in a fall in cardiac output $(21,22,33)$. In the hypotensive patients in this report, these pressor drugs usually increased cardiac output and did not slow the heart, suggesting that a rise in arterial pressure to normal levels is not actively buffered by reflex adjustments. Three of the five hypotensive patients who had no increase in cardiac output during norepinephrine infusion reacted more like normal individuals. Although they were symptomatic from a reduction in arterial pressure, their control cardiac outputs were nearly normal, and norepinephrine produced cardiac slowing with no change or a slight fall in minute output.

Most of the hypotensive patients in this series exhibited an increase in calculated peripheral vascular resistance during administration of norepinephrine or angiotensin, but the pressor response in seven subjects was associated with no change or a fall in calculated resistance. A paradoxical fall in peripheral resistance during norepinephrine infusion also has been reported in hemorrhagic shock in dogs (8). The increased transmural pressure associated with the pressor response results in passive dilatation of the arterioles that could obscure an active vasoconstrictor effect. However, the absence of an increase in peripheral resistance also could be explained in some patients by the greatly augmented cardiac output, which might induce relaxation of reflex vasoconstriction. A myocardial effect of these drugs in the absence of peripheral vasoconstriction could be the result of an early failure of resistance vessel response (54) or of a dissociation between the myocardial and vasoconstrictor effects of the drugs (55).

The increase in cardiac stroke work during infusion of norepinephrine could be the result not only of a direct inotropic effect of the drug but also of venoconstriction, which reduces the capacity of the peripheral vascular bed and shifts blood centrally to increase cardiac filling pressure. In most 
instances, the increased right ventricular work load was accomplished with little or no rise in atrial pressure. Since left atrial pressures were not measured, assessment of changes in left ventricular filling pressure must be indirect. Central blood volume was calculated in this study from dye curves recorded from the femoral artery after injection of indicator in the right heart. In the absence of dramatic alterations in systemic flow distribution, changes in central blood volume should indicate changes primarily in the volume of the heart and pulmonary vascular bed. An increase in central blood volume without a rise in right atrial pressure or volume should reflect an increase in left heart filling pressure. Most of the patients had a modest increase in central blood volume during the norepinephrine infusion, and thus the increased left ventricular stroke work was probably accomplished in part by an increase in diastolic stretch of the ventricle (56). A similar response has been observed during administration of norepinephrine to dogs (57). Although we have observed patients with markedly impaired left ventricular function who have developed pulmonary edema during infusion of norepinephrine (28), this complication probably results from overdosage producing extreme elevations in aortic pressure and left ventricular work. With maintenance of blood pressure at normal levels, symptoms of pulmonary congestion did not occur in the present series of patients.

The importance of a normal blood volume with adequate stores in the venous capacitance vessels for mobilization into the central circulation is demonstrated in Figure 1. Hypovolemic patients treated with norepinephrine had significantly less augmentation of central blood volume and left ventricular stroke work and a trend toward a smaller increase in cardiac output than the normovolemic patients. These results in patients with no evidence of external blood loss point out the need for recognition of occult blood volume depletion and its correction before the introduction of norepinephrine therapy. The influence of blood volume on the hemodynamic response to norepinephrine may help to explain the conflicting results reported with norepinephrine in experimental hemorrhagic shock (7-13).

Although most patients exhibited an increase in central blood volume during infusion of angioten- sin, an increase in left ventricular stroke work occasionally occurred in the absence of evidence of increased cardiac volume. This improvement in ventricular function might result from the increased aortic pressure, which could increase coronary blood flow (58) or produce an apparent improvement in myocardial performance $(59,60)$. However, a direct effect of angiotensin on ventricular contractility must be considered. The possibility of an inotropic effect of angiotensin specific for the depressed myocardium has been demonstrated by Downing in cats with oligemic shock (61). Although angiotensin may cause release of catecholamines (62), this phenomenon is probably unimportant in the inotropic effect of the drug $(26,63)$.

The increase in central blood volume that occurred in most of the patients during the infusion of angiotensin probably reflects increased left ventricular end diastolic volume and pressure (64, 65 ), and must be interpreted differently from that seen with norepinephrine. Angiotensin does not produce significant venoconstriction (36-38), and the central blood volume effects in this study were not related to the adequacy of intravascular volume. An increase in left heart volume implies a transient inequality in the outputs of the right and left ventricles. Since angiotensin has little, if any, constrictor effect on the pulmonary vasculature $(36,50,64)$, it is likely that the systemic vasoconstriction produced by an infusion would acutely increase left ventricular pressure work and result in a greater stroke volume from the right than the left ventricle (36). The blood accumulated in the lesser circulation would augment left ventricular filling and, in the presence of a competent heart, restore left ventricular output to match that from the right ventricle. Three patients in this series with severe myocardial disease developed evidence of acute left ventricular failure during the administration of angiotensin, suggesting that they could not adequately augment stroke work in response to an increase in filling pressure. However, most hypotensive patients, even those with acute myocardial infarctions, had no adverse effects during the infusion of angiotensin.

Conclusions as to the therapeutic efficacy of norepinephrine and angiotensin should be based upon knowledge of their regional hemodynamic and metabolic effects in hypotensive patients. But 
until these studies can be performed, the cardiac output must serve as an indicator of effects on blood flow. In patients with heart failure, where a potent inotropic stimulus may be an important factor, norepinephrine was considerably more effective than angiotensin in increasing cardiac output. When cardiac function was not impaired, and particularly when blood volume was depleted, both drugs produced similar effects on cardiac output.

Despite the increase in cardiac output, which frequently accompanied the infusion of norepinephrine and angiotensin in these hypotensive patients, output was restored to a normal range by these agents in only 6 of the 31 subjects. Therefore, although these drugs may be helpful in temporary support of the circulation, more effective means should always be sought to correct the individual patient's hemodynamic abnormality.

\section{Summary}

The hemodynamic effects of norepinephrine and angiotensin were studied in 31 patients with nonhemorrhagic shock or hypotension.

The rise in blood pressure with norepinephrine was accompanied by a slight increase in heart rate and an increase in cardiac output in most subjects, although the increase was attenuated in those patients with a reduced total blood volume. Peripheral vascular resistance was increased by the drug, but usually not to so great an extent as the cardiac output, and in several patients calculated resistance was not significantly increased. Central blood volume was increased in most patients, but care in preventing excessive blood pressure rises may have been responsible for the absence of episodes of pulmonary congestion in these patients.

Blood pressure was adequately controlled by angiotensin in all but three of the patients. Cardiac output was increased during 14 of the infusions and fell during 7,5 of which were in patients with congestive heart failure. An increase in left ventricular stroke work was accompanied by evidence of increased cardiac filling pressure in most patients, but improved myocardial function during angiotensin infusion was demonstrated in some subjects. The increase in central blood volume usually was asymptomatic, but three patients with heart disease developed acute left ventricular failure requiring discontinuation of the drug.

Direct comparison between the hemodynamic effects of equipressor doses of the two drugs in 16 patients revealed that norepinephrine produced a slightly higher cardiac output than angiotensin. Norepinephrine was considerably more effective in patients with heart failure but not in those with reduced blood volumes.

The data indicate that these pressor drugs usually increase the cardiac output in hypotensive patients. The need for correction of occult volume depletion before administering norepinephrine and for caution in the use of angiotensin in patients with left ventricular failure is stressed. Since cardiac output was increased to normal in only six patients, it is suggested that these drugs seldom correct the hemodynamic abnormality and should be viewed primarily as emergency supportive therapy.

\section{Acknowledgments}

We thank Dr. Edward D. Freis for his encouragement and advice and Miss Ann Eustace for her valuable technical assistance.

\section{References}

1. Nickerson, M. Drug therapy of shock in Shock, Pathogenesis and Therapy, K. D. Bock, Ed. Berlin, Springer-Verlag, 1962, p. 356.

2. Kurland, G. S., and M. Malach. The clinical use of norepinephrine in the treatment of shock accompanying myocardial infarction and other conditions. New Engl. J. Med. 1952, 247, 383.

3. Miller, A. J., A. Shifrin, B. M. Kaplan, H. Gold, A. Billings, and L. N. Katz. Arterenol in treatment of shock. J. Amer. med. Ass. 1953, 152, 1198.

4. Moyer, J. H., J. M. Skelton, and L. C. Mills. Norepinephrine: effect in normal subjects; use in treatment of shock unresponsive to other measures. Amer. J. Med. 1953, 15, 330.

5. Eckenhoff, J. E., and R. D. Dripps. The use of norepinephrine in various states of shock. Anesthesiology 1954, 15, 681 .

6. Nickerson, M. Factors of vasoconstriction and vasodilatation in shock. J. Mich. med. Soc. 1955, 54, 45.

7. Gilmore, J. P. Effectiveness of levarterenol during hemorrhagic hypotension. Amer. J. Physiol. 1958, 195, 473 .

8. Lansing, A. M., and J. A. F. Stevenson. Mechanism of action of norepinephrine in hemorrhagic shock. Amer. J. Physiol. 1958, 193, 289. 
9. Levy, M. N., and S. H. Brind. Influerce of $l$-norepinephrine upon cardiac output in anesthetized dogs. Circulat. Res. 1957, 5, 85.

10. Catchpole, B. N., D. B. Hackel, and F. A. Simeone. Coronary and peripheral blood flow in experimental hemorrhagic hypotension treated with l-norepinephrine. Ann. Surg. 1955, 142, 372.

11. Fowler, N. O., and R. Franch. Mechanism of pressor response to $l$-norepinephrine during hemorrhagic shock. Circulat. Res. 1957, 5, 153.

12. Gilmore, J. P., C. M. Smythe, and S. W. Handford. The effect of $l$-norepinephrine on cardiac output in the anesthetized dog during graded hemorrhage. J. clin. Invest. 1954, 33, 884.

13. Frank, E. D., H. A. Frank, S. Jacob, H. A. E. Weizel, H. Korman, and J. Fine. Effect of norepinephrine on circulation of the dog in hemorrhagic shock. Amer. J. Physiol. 1956, 186, 74.

14. Gilbert, R. P., K. P. Honig, J. A. Griffin, R. J. Becker, and B. H. Adelson. Hemodynamics of shock due to infection. Stanf. med. Bull. 1955, 13, 239.

15. Sambhi, M. B., M. H. Weil, V. N. Udhoji, and L. Rosoff. Effect of pressor amines on cardiac output in patients with acute hypotension. Circulation 1964, 30, 485.

16. Smulyan, H., R. P. Cuddy, and R. H. Eich. Hemodynamic effects of pressor agents in septic and myocardial infarction shock. J. Amer. med. Ass. 1964, 190, 188.

17. Del Greco, F., and D. C. Johnson. Clinical experience with angiotensin II in the treatment of shock. J. Amer. med. Ass. 1961, 178, 994.

18. Wedeen, R., and G. Zucker. Angiotensin II in the treatment of shock. Amer. J. Cardiol. 1963, 11, 82.

19. Nassif, A. C., T. R. Nolan, and A. C. Corcoran. Angiotensin II in treatment of hypotensive states. J. Amer. med. Ass. 1963, 183, 751.

20. McQueen, E. G., and R. B. I. Morrison. The effects of synthetic angiotensin and noradrenaline on blood pressure and renal function. Brit. Heart J: 1961, 23, 1.

21. Segel, N., P. Harris, and J. M. Bishop. The effects of synthetic hypertensin on the systemic and pulmonary circulations in man. Clin. Sci. 1961, 20, 49.

22. Finnerty, F. A., Jr., G. D. Massaro, V. Chupkovich, and J. Tuckman. Evaluation of the pressor, cardiac, and renal hemodynamic properties of angiotensin II in man. Circulat. Res. 1961, 9, 256.

23. Johnson, W. P., and R. A. Bruce. Hemodynamic and metabolic effects of angiotensin II during rest and exercise in normal healthy subjects. Amer. Heart J. 1962, 63, 212.

24. De Bono, E., G. De J. Lee, F. R. Mottram, G. W. Pickering, J. J. Brown, H. Keen, W. S. Peart, and $P$. H. Sanderson. The action of angiotensin in man. Clin. Sci. 1963, 25, 123.
25. Miller, A. J., and B. M. Kaplan. The therapy of cardiogenic shock. Ann. intern. Med. 1963, 58, 901.

26. Fowler, N. O., and J. C. Holmes. Coronary and myocardial actions of angiotensin. Circulat. Res. 1964, 14, 191.

27. Udhoji, V. N., and M. H. Weil. Circulatory effects of angiotensin, levarterenol and metaraminol in the treatment of shock. New Engl. J. Med. 1964, 270, 501.

28. Cohn, J. N., and M. H. Luria. Studies in clinical shock and hypotension. The value of bedside hemodynamic observations. J. Amer. med. Ass. 1964, 190, 891.

29. Hamilton, W. F., J. W. Moore, J. M. Kinsman, and R. G. Spurling. Studies on the circulation. Further analysis of the injection method, and of changes in hemodynamics under physiological and pathological conditions. Amer. J. Physiol. 1932, 99, 534

30. Gibson, J. G., 2nd., and W. A. Evans, Jr. Clinical studies of the blood volume. I. Clinical application of a method employing the azo dye "Evans blue" and the spectrophotometer. J. clin. Invest. 1937, 16,301 .

31. Owen, C. A., Jr., and M. H. Power. Intercellular plasma of centrifuged human erythrocytes as measured by mean of iodo ${ }^{131}$-albumin. J. appl. Physiol. 1953, 5, 323.

32. Gregersen, M. I., and R. A. Rawson. Blood volume. Physiol. Rev. 1959, 39, 307.

33. Goldenberg, M., K. L. Pines, E. de F. Baldwin, D. G. Green, and C. E. Roth. The hemodynamic response of man to norepinephrine and epinephrine and its relation to the problem of hypertension. Amer. J. Med. 1948, 5, 792.

34. Eckstein, J. W., and W. K. Hamilton. The pressurevolume responses of human forearm veins during epinephrine and norepinephrine infusions. J. clin. Invest. 1957, 36; 1663.

35. Rose, J. C., and E. D. Freis. Alterations in systemic vascular volume of the $\mathrm{dog}$ in response to hexamethonium and norepinephrine. Amer. J. Physiol. 1957, 191, 283.

36. Rose, J. C., P. A. Kot, J. N. Cohn, E. D. Freis, and G. E. Eckert. Comparison of effects of angiotensin and norepinephrine on pulmonary circulation, systemic arteries and veins, and systemic vascular capacity in the dog. Circulation 1962, 25, 247.

37. Haddy, F. J., J. I. Molnar, C. W. Borden, and E. C. Texter, Jr. Comparison of direct effects of angiotensin and other vasoactive agents on small and large blood vessels in several vascular beds. Circulation 1962, 25, 239.

38. De Pasquale, N. P., and G. E. Burch. Effects of angiotensin II on the intact forearm veins of man. Circulat. Res. 1963, 13, 239.

39. Goldberg, L. I., M. deV. Cotten, T. D. Darby, and E. V. Howell. Comparative heart contractile force 
effects of equipressor doses of several sympathomimetic amines. J. Pharmacol. exp. Ther. 1953, 108, 177.

40. Goldberg, L. I., R. D. Bloodwell, E. Braunwald, and A. G. Morrow. The direct effects of norepinephrine, epinephrine, and methoxamine on myocardial contractile force in man. Circulation 1960, 22, 1125.

41. Wilkins, R. W., and C. N. Duncan. The nature of the arterial hypertension produced in normal subjects by the administration of angiotonin. J. clin. Invest. 1941, 20, 721.

42. Middleton, S., and C. J. Wiggers. The effects of renin and angiotonin on cardiac output and total peripheral resistance. Amer. J. Physiol. 1944, 141, 128.

43. Downing, S. E., and E. H. Sonnenblick. Effects of continuous administration of angiotensin II on ventricular performance. J. appl. Physiol. 1963, 18, 585.

44. Binnion, P. F., and J. D. Hatcher. Cardiovascular effects of infusions of epinephrine and angiotensin singly and in combination. Circulat. Res. 1963, 12, 393.

45. Hill, W. H. P., and E. C. Andrus. Effects of renin and of angiotonin upon isolated perfused heart. Proc. Soc. exp. Biol. (N. Y.) 1940, 44, 213.

46. Lorber, V. The action of angiotonin on the completely isolated mammalian heart. Amer. Heart J. 1942, 23, 37.

47. Bianchi, A., A. F. De Schaepdryver, G. R. De Vleeschhouwer, and P. Preziosi. On the pharmacology of synthetic hypertensine. Arch. int. Pharmacodyn. 1960, 124, 21.

48. Koch-Weser, J. Myocardial actions of angiotensin. Circulat. Res. 1964, 14, 337.

49. Berry, W. B., W. G. Austen, and W. D. Clark. Studies on the relative cardiac and peripheral actions of angiotensin. Ann. Surg. 1964, 159, 520.

50. Yu, P. N., M. N. Luria, J. K. Finlayson, C. A. Stanfield, H. Constantine, and F. J. Flatley. The effects of angiotensin on pulmonary circulation and ventricular function. Circulation 1961, 24, 1326.

51. Heymans, C., and E. Neil. Reflexogenic Areas of the Cardiovascular System. Boston, Little, Brown, 1958.

52. Sarnoff, S. J., J. P. Gilmore, S. K. Brockman, J. H. Mitchell, and R. J. Linden. Regulation of ventricular contraction by the carotid sinus. Its effect on atrial and ventricular dynamics. Circulat. Res. 1960, 8, 1123.

53. De Geest, H., M. N. Levy, and H. Zieske, Jr. Carotid sinus baroreceptor reflex effects upon myocardial contractility. Circulat. Res. 1964, 15, 327.

54. Lewis, D. H., and S. Mellander. Competitive effects of sympathetic control and tissue metabolites on resistance and capacitance vessels and capillary filtration in skeletal muscle. Acta physiol. scand. 1962, 56, 162.

55. Sarnoff, S. J., R. B. Case, E. Berglund, and L. C. Sarnoff. Ventricular function. V. The circulatory effects of aramine; mechanism of action of "vasopressor" drugs in cardiogenic shock. Circulation 1954, 10, 84.

56. Sarnoff, S. J., and J. H. Mitchell. The regulation of the performance of the heart. Amer. J. Med. 1961, 30, 747.

57. Shadle, O. W., J. C. Moore, and D M.. Billing. Effect of $l$-arterenol infusion on "central blood volume" in the dog. Circulat. Res. 1955, 3, 385.

58. Braunwald, E., S. J. Sarnoff, R. B. Case, W. N. Stainsby, and G. H. Welch, Jr. Hemodynamic determinants of coronary flow: effect of changes in aortic pressure and cardiac output on the relationship between myocardial oxygen consumption and coronary flow. Amer. J. Physiol. 1958, 192, 157.

59. Sonnenblick, E. H., and S. E. Downing. Afterload as a primary determinant of ventricular performance. Amer. J. Physiol. 1963, 204, 604.

60. Sarnoff, S. J., J. H. Mitchell, J. P. Gilmore, and J. P. Remensnyder. Homeometric autoregulation in the heart. Circulat. Res. 1960, 8, 1077.

61. Downing, S. E. Effects of angiotensin II and norepinephrine on ventricular performance during oligemic shock. Yale J. Biol. Med. 1964, 36, 407.

62. Feldberg, W., and G. P. Lewis. The action of peptides on the adrenal medulla. Release of adrenaline by bradykinin and angiotensin. J. Physiol. (Lond.) 1964, 171, 98.

63. Koch-Weser, J. Nature of the inotropic action of angiotensin on ventricular myocardium. Circulat. Res. 1965, 16, 230.

64. Sancetta, S. M. General and pulmonary hemodynamic effects of pure decapeptide angiotensin in normotensive man. Circulat. Res. 1960, 8, 616.

65. Ross, J., Jr., and E. Braunwald. The study of left ventricular function in man by increasing resistance to ventricular ejection with angiotensin. Circulation $1964,29,739$. 